\title{
COVID-19 Disease and Risk Perception Among Healthcare Professionals in Guinea
}

\author{
Alexandre Delamou ${ }^{1,2, ~ *, ~ F a s s o u ~ M a t h i a s ~ G r o v o g u i ~}{ }^{2}$, Delphin Kolie ${ }^{2}$, Thierno Oumar Fofana ${ }^{1}$, \\ Karifa Kourouma $^{2}$, Sidikiba Sidibe ${ }^{1,2}$, Graziella Ghesquiere ${ }^{3}$ \\ ${ }^{1}$ Africa Center of Excellence for Prevention and Control of Communicable Diseases (CEA-PCMT), University Gamal Abdel Nasser, \\ Conakry, Guinea \\ ${ }^{2}$ Maferinyah National Training and Research Centre, Forécariah, Guinea \\ ${ }^{3}$ Belgian Development Agency (ENABEL), Conakry, Guinea
}

\section{Email address:}

adelamou@cea-pcmt.org (A. Delamou), mgrovogui@maferinyah.org (F. M. Grovogui), dkolie@maferinyah.org (D. Kolie), tfofana@cea-pcmt.org (T. O. Fofana), kkourouma@maferinyah.org (K. Kourouma), layesidibe@gmail.com (S. Sidibe), graziella.ghesquiere@enabel.be (G. Ghesquiere)

*Corresponding author

\section{To cite this article:}

Alexandre Delamou, Fassou Mathias Grovogui, Delphin Kolie, Thierno Oumar Fofana, Karifa Kourouma, Sidikiba Sidibe, Graziella Ghesquiere. COVID-19 Disease and Risk Perception Among Healthcare Professionals in Guinea. European Journal of Preventive Medicine. Vol. 9, No. 2, 2021, pp. 32-38. doi: 10.11648/j.ejpm.20210902.11

Received: February 14, 2021; Accepted: March 1, 2021; Published: March 9, 2021

\begin{abstract}
The COVID-19 pandemic represents a public health challenge for health systems in the developing world. The objective of this study was to assess, among healthcare professionals in Guinea, the factors associated with COVID-19 perceived susceptibility and severity. We conducted a cross-sectional study in April 2020 among 1058 healthcare professionals as part of the rapid assessment of the Guinean health system preparedness and response to the COVID-19 pandemic. The median level of perceived susceptibility to COVID-19 among healthcare professionals was 6 (IQR: 6-10). About 74.57\% of participants said that the COVID-19 was more severe in the elderly than in other age groups. Overall, $41.97 \%$ of participants said that healthcare professionals were more prone to get COVID-19 than other professionals, and $67.58 \%$ said that the risk of contracting COVID-19 in healthcare facilities was higher than anywhere else. Being a woman $(\beta=0.37$ [0.02;0.73]), an allied healthcare professional $(\beta=0.64[0.23 ; 1.06])$, perceiving the elderly as more likely to contract COVID-19 ( $\beta=0.48[0.11 ; 0.86])$ and accepting the closure of places of worship $(\beta=0.47[0.00 ; 0.93])$ were predictors of higher perceived level of susceptibility to COVID-19. The level of perceived susceptibility to COVID-19 was very high among health professionals in the early stages of the COVID-19 pandemic in Guinea. Strategies to empower and improve health professionals' knowledge are needed to balance their provision of good quality care to patients with their responsibility and ability to protect themselves and their families.
\end{abstract}

Keywords: COVID-19, Risk Perception, Healthcare Professional, Guinea

\section{Introduction}

On March 11, 2020, the World Health Organization (WHO) declared the novel coronavirus 19 disease (COVID-19) as a pandemic [1]. As of July 31, 2020, it had affected over 14 million people worldwide and 607,781 deaths, making it the largest pandemic of the $21^{\text {st }}$ century [2]. Even though the morbidity (4.2\%) and mortality (1.6\%) due to the COVID-19 pandemic in Africa are relatively low compared with other parts of the world, the disease is jeopardizing the already under-resourced and fragile health systems, in particular those of sub-Saharan Africa (SSA) [3, 4]. To avert the virus's spread, WHO recommends, among others, preventive and control measures, social distancing, handwashing, use of face masks, and lockdown [5, 6]. However, these measures constitute another concern in the African context, given the 
socio-cultural norms and perceptions on gathering and handshaking [6, 7]. Furthermore, rumors circulating about the cures of COVID-19 pandemic and healthcare professionals' role in spreading the disease might encourage the general population to undermine the disease-related risk and act in contradiction to public health measures; thus favoring the spread of the virus [8,9]. Risk perception is a crucial determinant of healthcare professionals' attitudes during a public health emergency [10]. A high perceived risk of contracting a disease may push people to take protective actions to reduce such risks [11, 12]. Recent studies conducted among healthcare professionals in Eastern (Ethiopia) and Northern (Egypt) Africa have reported high levels of perceived risks of contamination among healthcare professionals, and severity of the disease; which were associated with better adherence to preventive and control measures $[10,13]$.

In Guinea, while the first case of COVID-19 was officially declared on March 12, 2020, over 10,750 confirmed cases and 66 deaths have been recorded as of October 3, 2020 [14]. The majority occurred in the capital city Conakry. To date, Guinea is among the countries most affected by the COVID19 pandemic in West Africa [2]. In April 2020, a rapid situational analysis was conducted in Guinea to evaluate the national health system preparedness in responding to the COVID-19 pandemic, including data on how healthcare professionals perceive the disease and public response. This paper aims to assess, among healthcare professionals in Guinea, the factors associated with the level of perceived susceptibility to and severity of COVID-19. This study's relevance lies in its potential to influence risk communication strategies for healthcare professionals to ensure that appropriate procedures are maintained and to prevent emotional distress among healthcare professionals during the ongoing epidemic in Guinea and in neighboring countries with similar contexts.

\section{Methods}

\subsection{Study Design and Period}

This was a cross-sectional study conducted as part of the rapid assessment of the Guinean health system preparedness and response to the COVID-19 pandemic. The study was carried from April 10 to 25, 2020.

\subsection{Study Setting}

Guinea is a country located in West African with approximately 12 million inhabitants, the minority of which are literate (33\%) and live in rural areas (64\%). Also, 55\% of this population lives below the national poverty line (less than 1 US dollar per day) [15].

The country comprises 38 health districts including the capital, Conakry. The national public health system is tired into three distinct levels of care provision: primary (413 health centers and 910 health posts), secondary (seven regional hospitals, 26 district hospitals, and eight medico- communal centers) and tertiary (three national hospitals) levels [15].

Issues of the shortages and geographical imbalance of healthcare professionals constitute one of the bottlenecks for the national health system performance [16-18]. In 2014, the ratio of healthcare professionals was 7.25 per 10,000 inhabitants, and $55 \%$ of them staying in the capital, Conakry, where lives only $15 \%$ of the population [17]. Another concern, not the least, is the low presence (absenteeism) of public healthcare professionals, especially in rural settings [16].

\subsection{Study Sites}

The study took place in 13 health districts including Ratoma, Dixinn Kaloum, Matoto and Matam (in Conakry), Kindia, Mamou, Labé, Kankan, N'Zérékoré, Lola, Siguiri and Mali. The study sites were selected based on the potential for substantial traffic and commercial connections. Considering the dynamics of COVID-19, we assumed that the virus's risk was higher through the major axes of mobility and trade.

\subsection{Study Population}

The study population was composed of healthcare professionals from the all-selected study sites, aged 18 years and above, who consented to participate.

\subsection{Study Variables}

\subsubsection{Dependent Variable}

The level of perceived susceptibility toward COVID-19 among healthcare professionals was our outcome of interest. This variable was measured by asking the respondent to rate on a scale of 1 to 10 their level of fear of contracting COVID-19, where 1 means no fear and 10 means a lot of fear.

\subsubsection{Independent Variables}

The independent variables included in this study were: age, gender, region, healthcare professional category, work experience, workplace, knowledge of COVID-19 (Type of disease, host, modes of transmission, the definition of suspect case, and prevention measures), perceived susceptibility to COVID-19 by sociodemographic characteristics (age, race, profession, socio-economic group), perceived severity of COVID-19 by age and race, perceived risk of contracting COVID-19 in different places (health facilities, when staying at home and crowded places), level of satisfaction about the overall measures to fight COVID-19 in services and country, opinion about the general measures implemented to contain the spread of the virus (reduction of the number of passengers in public transportations, travel ban from the capital city (Conakry), closure of schools, mosques and churches). To better explain our outcome of interest in bivariate and multivariate analyses, some independent variables were recoded (supplementary material). 


\subsection{Sources and Data Collection}

The study proceeds to a stratified sampling by zone (Conakry and the countryside). A total of 169 health facilities including 49 health centers, 120 hospitals/CMCs and private clinics were selected using simple random sampling method. In health services or health centers, 5 to 10 healthcare professionals were included in the study for a total of 1058 healthcare professionals.

The data were collected using a standardized and structured questionnaire administered by a team of 20 data collectors (Masters of Public Health students and graduate physicians) after training on the study protocol and data collection tools. The questionnaire was developed electronically on the Kobotoolbox platform, downloaded on tablets and administered in-person to participants. Few questionnaires were sent by e-mail (approximately 15\%) to healthcare professionals physically inaccessible. A pilot phase was conducted to pre-test the questionnaire with a group of 20 medical students in Conakry.

\subsection{Data Analysis}

Data from excel were cleaned and imported into Stata (Stata Corporation, College Station, TX, USA) for analysis. Data were summarized using descriptive statistics (proportion and median with interquartile range). Bivariate analysis was done to assess the relationship between each independent variable and the dependent variable separately. A multivariate model was then constructed using the likelihood-ratio test (LRT) for goodness-of-fit of successive models, initially including variables. Variables with a pvalue less than or equal to 0.05 on the LRT were retained in the final linear model. The final model was constructed after checking for multicollinearity between the independent variables. Results were reported using the coefficient with $95 \%$ confidence intervals (CI) with a significance level set at $\mathrm{p}<0.05$.

\subsection{Ethics Considerations}

This study was approved by the National Ethics Committee for Health and Research in Guinea $\left(\mathrm{N}^{\circ}\right.$ : 042/CNERS/20). Informed consent was obtained from all participants before the conduction of the survey.

\section{Results}

\subsection{Sociodemographic Characteristics}

The sociodemographic characteristics of participants are shown in Table 1. Out of 1,058 respondents included in the analysis, $50.57 \%$ were male and $84.59 \%$ were aged $25-49$ years with a median age of 34 years (IQR 28-39). About $55.10 \%$ of them lived outside the capital city (Conakry) and $84.78 \%$ worked in public facilities. Medical doctors represented more than one-fourth of the sample (27.88\%) and about $61.00 \%$ of the respondents had more than 5 years of work experience.
Table 1. Sociodemographic characteristics of the healthcare professionals who participated in the study, Guinea $(N=1058)$.

\begin{tabular}{lll}
\hline Sociodemographic characteristics & Number & Percentage \\
\hline Age group (Year) & 75 & 7.09 \\
$18-24$ & 895 & 84.59 \\
$25-49$ & 88 & 8.32 \\
$50+$ & & \\
Sex & 535 & 50.57 \\
Female & 523 & 49.43 \\
Male & & \\
Region & 475 & 44.90 \\
Conakry & 583 & 55.10 \\
Other regions & & \\
Healthcare professionals & 763 & 72.12 \\
Allied healthcare professionals & 295 & 27.88 \\
Doctors & & \\
Work experience (Year) & 419 & 39.60 \\
0-4 & 639 & 60.40 \\
5 and more & & \\
Category of facility & 161 & 15.22 \\
Private & 897 & 84.78 \\
Public & & 10.59 \\
Workplace & 112 & 22.59 \\
National Hospital & 239 & 20.51 \\
Regional Hospital & 217 & 30.15 \\
District Hospital & 319 & 16.16 \\
Health Center & 171 & \\
Private facility & & \\
\hline
\end{tabular}

Table 2. Healthcare professionals' perceptions of the susceptibility to COVID-19 by sociodemographic characteristics.

\begin{tabular}{lll}
\hline $\begin{array}{l}\text { Sociodemographic } \\
\text { characteristics }\end{array}$ & $\begin{array}{l}\text { Susceptibility } \mathbf{n} \\
(\mathbf{\%})\end{array}$ & Severity n (\%) \\
\hline Age group & & \\
Children & $12(1.13)$ & $10(0.95)$ \\
Youth & $6(0.57)$ & $0(0.00)$ \\
Adults & $33(3.12)$ & $13(1.23)$ \\
Elderly & $554(52.36)$ & $789(74.57)$ \\
Everybody & $450(42.53)$ & $239(22.59)$ \\
Don't know & $3(0.28)$ & $7(0.66)$ \\
Race & & \\
Asian & $11(1.04)$ & $9(0.85)$ \\
White & $284(26.84)$ & $417(39.41)$ \\
Black & $4(0.38)$ & $3(0.28)$ \\
Mestizo & $3(0.28)$ & $1(0.09)$ \\
Everybody & $747(70.60)$ & $621(58.70)$ \\
Don't know & $9(0.85)$ & $7(0.66)$ \\
Professional group & & \\
Other professions & $131(12.38)$ & NA \\
Healthcare professionals & $444(41.97)$ & NA \\
Everybody & $483(45.65)$ & NA \\
Socio-economic group & & \\
Poor & $48(4.54)$ & NA \\
Middle class & $3(0.28)$ & NA \\
Rich & $219(20.70)$ & NA \\
Everybody & $774(73.16)$ & NA \\
Don't know & $14(1.32)$ & NA \\
\hline
\end{tabular}

\subsection{Participants Perceptions of the Susceptibility to COVID-19}

Table 2 shows the perceptions of the participants about COVID-19 susceptibility and severity. Only $42.53 \%$ of the participants said that people of all age groups were equally susceptible to COVID-19 but $70.60 \%$ said people of all races were similarly susceptible to the disease. Healthcare 
professionals (41.97\%) were found more susceptible to COVID19 than other professions, but $73.16 \%$ of participants thought all socio-economic groups were equally susceptible to COVID- 19. Nonetheless, one-fifth $(20.70 \%)$ of the participants felt that people in a richer socioeconomic group were more susceptible to the virus. As for disease severity, $74.57 \%$ of participants said that the seriousness of COVID-19 was higher in older people than other age groups. Also, only $58.70 \%$ said the disease was equally severe across all races (39.41\%) of participants perceived COVID-19 more severe in White people as compared to other races).

The perception of the risk of contracting COVID-19 by type of place is presented in Table 3 . The majority of the participants thought that the risk of contracting COVID-19 was high or very high in health facilities $(67.58 \%)$ and crowded places $(96.22 \%)$ but not when staying at home $(12.10 \%)$.

On a scale of 10 , the median level of perceived susceptibility toward COVID-19 among healthcare professionals was 6 (IQR: 6-10).

Table 3. Healthcare professionals' perceptions of the susceptibility to COVID-19 by type of place.

\begin{tabular}{|c|c|c|c|c|c|}
\hline Type of place & Low-risk n (\%) & More/less risk n (\%) & High-risk n (\%) & Very high-risk n (\%) & Don't know n (\%) \\
\hline Health facility & $137(12.95)$ & $195(18.43)$ & $318(30.06)$ & $397(37.52)$ & $11(1.04)$ \\
\hline When staying at home & $710(67.11)$ & $215(20.32)$ & $92(8.70)$ & $36(3.40)$ & $5(0.47)$ \\
\hline In crowded places & $11(1.04)$ & $28(2.65)$ & $212(20.04)$ & $806(76.18)$ & $1(0.09)$ \\
\hline
\end{tabular}

\subsection{Factors Associated with an Increased Level of Perceived Susceptibility Toward COVID-19 Among Healthcare Professionals in Guinea}

Results of unadjusted and adjusted logistic regressions are shown in table 4. Variables independently associated with the level of perceived susceptibility toward COVID-19 included gender, healthcare professional category, workplace and COVID-19 knowledge score.
In multivariate analysis we found that being a woman $(\beta=0.37[0.02 ; 0.73])$, an allied healthcare professional $(\beta=0.64[0.23 ; 1.06])$, perceiving elderly as more susceptible to COVID-19 $(0.48[0.11 ; 0.86])$ and agreeing with the closure of worship places $(\beta=0.47[0.00 ; 0.93])$ were positively associated with a higher perceived susceptibility of COVID-19. However, the increase of the knowledge score $(\beta=-0.11[-0.20 ;-0.02])$ was negatively associated with a higher perceived susceptibility of COVID-19.

Table 4. Factors associated with an increased level of perceived susceptibility toward COVID -19 among healthcare professionals in Guinea.

\begin{tabular}{|c|c|c|c|c|}
\hline \multirow{2}{*}{ Characteristics } & \multicolumn{2}{|c|}{ Bivariate linear model } & \multicolumn{2}{|c|}{ Multivariate linear model } \\
\hline & Coef (CI95\%) & pvalue & Coef (CI95\%) & pvalue \\
\hline \multicolumn{5}{|l|}{ Age groups } \\
\hline $18-24$ & Ref & & Ref & \\
\hline $25-49$ & $-0.37[-1.00 ; 0.27]$ & 0.260 & $-0.02[-0.66 ; 0.62]$ & 0.948 \\
\hline $50+$ & $-0.50[-1.33 ; 0.34]$ & 0.241 & $-0.27[-1.09 ; 0.56]$ & 0.527 \\
\hline \multicolumn{5}{|l|}{ Gender } \\
\hline Male & Ref & & Ref & \\
\hline Female & $0.77[0.45 ; 1.10]$ & 0.000 & $0.37[0.02 ; 0.73]$ & 0.041 \\
\hline \multicolumn{5}{|l|}{ Healthcare professionals } \\
\hline Doctors & Ref & & Ref & \\
\hline Allied healthcare professionals & $0.95[0.59 ; 1.31]$ & 0.000 & $0.64[0.23 ; 1.06]$ & 0.002 \\
\hline \multicolumn{5}{|l|}{ Workplace } \\
\hline National Hospital & Ref & & Ref & \\
\hline Regional Hospital & $-0.03[-0.63 ; 0.58]$ & 0.929 & $-0.36[-0.97 ; 0.25]$ & 0.246 \\
\hline District Hospital & $0.66[0.05 ; 1.28]$ & 0.034 & $0.40[-0.21 ; 1.01]$ & 0.203 \\
\hline Health Center & $0.62[0.04 ; 1.20]$ & 0.035 & $0.28[-0.30 ; 0.87]$ & 0.344 \\
\hline Private facility & $-0.01[-0.65 ; 0.63]$ & 0.977 & $0.11[-0.53 ; 0.74]$ & 0.746 \\
\hline Knowledge score & $-0.17[-0.24 ;-0.09]$ & 0.000 & $-0.11[-0.20 ;-0.02]$ & 0.013 \\
\hline \multicolumn{5}{|l|}{ Perceived severity by age group } \\
\hline Other & Ref & & Ref & \\
\hline Elderly & $0.30[-0.08 ; 0.67]$ & 0.118 & $0.48[0.11 ; 0.86]$ & 0.012 \\
\hline \multicolumn{5}{|c|}{ Perceived susceptibility by profession } \\
\hline Healthcare professionals & $0.16[-0.17 ; 0.49]$ & 0.341 & $0.10[-0.23 ; 0.42]$ & 0.561 \\
\hline \multicolumn{5}{|l|}{ Worship places closure } \\
\hline Disagree & Ref & & Ref & \\
\hline Agree & $0.34[-0.13 ; 0.80]$ & 0.159 & $0.47[0.00 ; 0.93]$ & 0.050 \\
\hline
\end{tabular}

\section{Discussion}

To our knowledge, this study is one of the first study assessing the perceptions and factors associated with an increased level of perceived susceptibility to COVID-19 among healthcare professionals in Guinea. The study revealed a very high level of perceived risk of contracting the 
virus among study participants. The level of perceived susceptibility by age group was low among them, while their perceived severity of COVID-19 in the same group was very high. Besides, the proportion of participants who thought healthcare professionals were more sensitive to COVID-19 was significant. Furthermore, a higher proportion thought that the risk of contracting COVID-19 in healthcare facilities was greater. Finally, the multivariate analysis revealed that being a woman, being an allied healthcare professional, perceiving the elderly as more likely to contract COVID-19 and accepting the closure of places of worship were predictors of an increase in the perceived level of susceptibility of healthcare professionals. In contrast, the knowledge score increase was negatively associated with a greater perceived sensitivity to COVID-19.

The study had some limitations that should be noted. First, this was a cross-sectional study, so participants' responses could be affected by their ability to remember correct answers at the interview time. Second, the study did not assess the correlation between participant's perception and attitudes and practices. Further studies are needed to measure this relation. Nonetheless, this study is unique in understanding healthcare professionals' perceptions of the current epidemic and their own risk of becoming infected by providing healthcare to populations. Therefore, the findings should influence strategy development to improve their knowledge and practices.

Findings show that respectively about two-fifths and threequarters of participants had adequate levels of perceived risk of contamination in all age groups and severe illness in older people. Besides, perceiving the elderly as more likely to contract COVID-19 and accepting the closure of worship places were predictors of an increase in the perceived level of susceptibility of healthcare professionals. From a public health perspective, these data are of particular interest. According to the $\mathrm{WHO}$, all age groups are susceptible to COVID-19 [19]. Still, severe illness risk is higher in people over 60 years of age or who present conditions such as lung or heart disease, diabetes, or conditions that affect their immune system [20]. The difference in level between the perceived susceptibility to COVID-19 and the severity of COVID-19 in the age groups might relate to the higher COVID-19 lethality in the elderly than other age groupss reported earlier in the pandemic course. Perceiving older people as more susceptible to COVID-19 and accepting the closure of places of worship were, in fact, positive predictors of increased perceived severity of COVID-19 among healthcare professionals. Indeed, this study was conducted nearly three weeks after the first confirmed COVID-19 cases in Guinea and attempted to examine the level of knowledge and perception of risk among healthcare professionals and the general population. Our data are consistent with those of Abdel Wahed et al., who found that $89.70 \%$ of healthcare professionals in Egypt recognize that the risk of severe illness due to COVID-19 is higher among the elderly than other age groups [13].

Results revealed that over two-fifths and two-thirds of participants had a poor understanding of susceptibility to COVID-19 in healthcare professionals and healthcare institutions. Moreover, the study revealed a high perceived level of susceptibility to COVID-19 among the study participants and multivariate analysis shows that being an allied healthcare professional was also a positive predictor of higher perceived susceptibility to COVID-19 in healthcare professionals. Our results show that healthcare professionals did not feel protected from COVID-19 in health facilities. This has implications for their attitudes towards COVID-19 and the quality and volume of health services provided to care seekers. In a similar study in Egypt, healthcare professionals reported the constant non-availability of Personal Protective Equipment (EPP) (83.60\%), promiscuity $(61.40 \%)$ and poor ventilation $(72.00 \%)$ in the workplace, and the fact that the population was not committed to taking preventive measures $(75.40 \%)$ as the main reasons for their susceptibility to COVID-19 [13]. Our data are consistent with the findings of Abdoul Wahed et al. and Zhou et al. who found that $89 \%$ and $85 \%$ of healthcare professionals, respectively, were afraid of being infected with the disease $[13,21]$. Also, the stress levels were high among healthcare professionals working and non-working in the management of COVID-19 during the first months after the outbreak of the pandemic [22].

We also found that an increase in participants' knowledge score decreased the level of perceived susceptibility to COVID-19 among study participants. Our results show that a better knowledge of the virus, its mode of transmission, signs, and evolution improve self-confidence to better protect oneself by adopting the right attitudes. Kassie et al., in their study among healthcare professionals in Ethiopia, found that healthcare professionals who had good knowledge of COVID-19 were three times more likely to have a positive attitude towards COVID-19 (AOR=3.17; 95\% CI: 1.97, 5.06) [23]. Our results contrast, however, with those found by Abdoul Wahed et al. who reported that despite their high knowledge score on COVID-19, nearly 9 out of 10 healthcare professionals felt at risk of infection [13] and confirms that an adequate level of training of healthcare professionals improves their level of confidence to protect themselves, their collaborators and their families.

\section{Conclusion}

In conclusion, this study revealed a high level of perceived susceptibility to COVID-19 among study participants in the early stages of the epidemic in Guinea. Gender, category of healthcare professionals, perceived susceptibility level by age group, acceptance of closure of places of worship, and knowledge score were associated with an increase in healthcare professionals' perceived susceptibility level. There is a need for strategies to improve all healthcare professionals' knowledge, not just those working in the management of COVID-19, to better balance their fundamental duty to provide good quality care to populations with their responsibility to protect themselves and their families. 


\section{Data Availability}

The data used to support the findings of this study are available from the corresponding author upon request.

\section{Conflict of Interest}

The authors declare they have no competing interests.

\section{Author Contributions}

AD, FMG, KK, DK and SS designed the study. FMG and AD performed the statistical analyses and developed the draft manuscript with inputs from DK, KK, SS and TOF. All authors critically reviewed and approved the final manuscript

\section{ORCID}

Alexandre Delamou https://orcid.org/0000-0002-93977106

Fassou Mathis Grovogui https://orcid.org/0000-00017356-9677

Delphin Kolié https://orcid.org/0000-0003-4705-0964

Thierno Oumar Fofana

Karifa Kourouma https://orcid.org/0000-0001-6375-262X

Sidikiba Sidibé https://orcid.org/0000-0002-7905-9042

Graziella Ghesquière

\section{Funding}

The Belgian Development Agency (Enabel) funded the study (agreement number GIN1701311-AP001). The Belgian Directorate of Development Cooperation through the Framework Agreement Four (FA4) provided additional funding through the Scientific Collaboration between the Institute of Tropical Medicine of Antwerp and the Maferinyah National Training and Research Centre in Rural Health (CNFRSR). The funders had no role in study design, data collection and analysis, decision to publish, or manuscript preparation.

\section{References}

[1] Cucinotta D, Vanelli M. WHO declares COVID-19 a pandemic. Acta Biomed. 2020; 91 (1): 157-60.

[2] World Health Organization. Coronavirus disease (COVID19)- Situation Report- 183 [Internet]. [cited 2021 January 21]. Available from: https://www.who.int/docs/defaultsource/wha-70-and-phe/20200721-covid-19-sitrep183.pdf?sfvrsn=b3869b3_2.

[3] World Health Organization. Maintaining essential health services: operational guidance for the COVID-19 context. Who. 2020; 1 (June): 1-55.

[4] World Health Organization. Media Statement: Knowing the risks for COVID-19 [Internet]. 2020 [cited 2020 August 7]. Available from: knowing-the-risk-for-covid-19\#.

[5] van Griensven J, Edwards T, de Lamballerie X, Semple MG, Gallian P, Baize S, et al. Evaluation of Convalescent Plasma for Ebola Virus Disease in Guinea. N Engl J Med. 2016 January 7; 374 (1): 33-42.

[6] World Health Organization. COVID-19 Strategy update [Internet]. [cited 2021 January 21]. Available from: https:/www.who.int/publications/m/item/covid-19-strategyupdate.

[7] Thiam S, Delamou A, Camara S, Carter J, Lama EK, Ndiaye $\mathrm{B}$, et al. Challenges in controlling the Ebola outbreak in two prefectures in Guinea: why did communities continue to resist? Pan Afr Med J. 2015; 22 (Suppl 1): 22.

[8] Obaji P. Efforts to Contain Coronavirus Spread in Africa Undermined by Misinformation [Internet]. 2020 [cited 2020 August 7]. Available from: https://heglobalobservatory.org/2020/04/efforts-containcoronavirus-spread-africa-undermined-misinformation/.

[9] Iorfa SK, Ottu IFA, Oguntayo R, Ayandele O, Kolawole SO, Gandi JC, et al. COVID-19 Knowledge, Risk Perception, and Precautionary Behavior Among Nigerians: A Moderated Mediation Approach. Front Psychol. 2020 Nov 20; 11.

[10] Deressa W, Worku A, Abebe W, Gizaw M. Risk perceptions and preventive practices of COVID-19 among healthcare professionals in public hospitals in Ethiopia. bioRxiv. 2020 Nov 4; 2020.11.04.367896.

[11] Brewer NT, Weinstein ND, Cuite CL, Herrington JE. Risk Perceptions and Their Relation to Risk Behavior. Ann Behav Med. 2004; 27 (2): 125-30.

[12] Chor JSY, Ngai KLK, Goggins WB, Wong MCS, Wong SYS, Lee N, et al. Willingness of Hong Kong healthcare workers to accept pre-pandemic influenza vaccination at different WHO alert levels: Two questionnaire surveys. BMJ. 2009 Sep; 339 (7721): 618

[13] Abdel Wahed WY, Hefzy EM, Ahmed MI, Hamed NS. Assessment of Knowledge, Attitudes, and Perception of Health Care Workers Regarding COVID-19, A CrossSectional Study from Egypt. J Community Health. 2020 December 7; 45 (6): 1242-51

[14] Agence Nationale de Sécurité Sanitaire. Rapport de Situation Epidémiologique (SITREP) au COVID-19, Guinée, N183 Octobre 2020. 2020. [French].

[15] Guinée. Institut National de la Statistique. Annuaire statistique 2018 [Internet]. 2018 [cited 2020 May 8]. p. 1-146. Available from: http:/www.statguinee.org/images/Documents/Publications/INS/annuelles/ann uaire/INS_annuaire_2018.pdf [French].

[16] Van De Pas R, Kolie D, Delamou A, Van Damme W. Health workforce development and retention in Guinea: A policy analysis post-Ebola. Hum Resour Health. 2019 August 5; 17 (1): 63 .

[17] Ministère de la Santé de la Guinée. Plan stratégique de développement des ressources, humaines en santé, OMS (WHO) 2/2013 [Internet]. [cited 2021 Jan 22]. Available from: https://portail.sante.gov.gn/document/plan-strategique-dedeveloppement-des-ressourceshumaines-en-sante-omswho-22013/ [French] 
[18] Jansen C, Codjia L, Dieleman M, Lamine Y, Cometto G. Realizing universal health coverage for maternal health services in the Republic of Guinea: the use of workforce projections to design health labor market interventions. Risk Manag Healthc Policy. 2014 Nov 20; 7: 219.

[19] World Health Organization. WHO delivers advice and support for older people during COVID-19 [Internet]. Who. 2020 [cited 2021 January 8]. Available from: https://www.who.int/newsroom/feature-stories/detail/who-delivers-advice-and-supportfor-older-people-during-covid-19.

[20] World Health Organization - Western Pacific. COVID-19 advice - High risk groups [Internet]. [cited 2021 January 20]. Available from: https://www.who.int/westernpacific/emergencies/covid19/information/high-risk-groups.
[21] Zhang M, Zhou M, Tang F, Wang Y, Nie H, Zhang L, et al. Knowledge, attitude, and practice regarding COVID-19 among healthcare workers in Henan, China. J Hosp Infect. 2020 June 1; 105 (2): 183-7.

[22] Man MA, Toma C, Motoc NS, Necrelescu OL, Bondor CI, Chis AF, et al. Disease perception and coping with emotional distress during covid-19 pandemic: A survey among medical staff. Int J Environ Res Public Health. 2020 July 1; 17 (13): 113.

[23] Kassie BA, Adane A, Tilahun YT, Kassahun EA, Ayele AS, Belew AK. Knowledge and attitude towards COVID-19 and associated factors among health care providers in Northwest Ethiopia. Pakpour AH, editor. PLoS One. 2020 Aug 28; 15 (8): e0238415. 